\title{
Bibliometric analysis of sharing economy logistics and crowd logistics
}

\author{
Laurence Saglietto \\ Université Côte d'Azur, GREDEG CNRS, France
}

\begin{abstract}
Purpose - This study aims to review the literature on sharing economy logistics and crowd logistics to answer the three following questions: How is the literature on sharing economy logistics structured? What are the main trends in sharing economy logistics and crowd logistics? What are the future research options?

Design/methodology/approach - Bibliometric analysis is used to evaluate 85 articles published over the past 12 years; it identifies the top academic journals, authors and research topics contributing to the field.

Findings - The sharing economy logistics and crowd logistics literature is structured around several disciplines and highlights that some are more scientifically advanced than others in their subject definitions, designs, modelling and innovative solutions. The main trends are organized around three clusters: Cluster 1 refers to the optimal allocation of costs, prices, distribution and supplier relationships; Cluster 2 corresponds to business related crowdsourcing and international industry practices; and Cluster 3 includes the impact of transport on last-mile delivery, crowd shipping and the environment.

Research limitations/implications - The study is based on data from peer-reviewed scientific journals and conferences. A broader overview could include other data sources such as books, book chapters, working papers, etc.

Originality/value - Future research directions are discussed in the context of the evolution from crowd logistics to crowd intelligence, and the complexities of crowd logistics such as understanding how the social crowd can be integrated into the logistics process. Our results are part of the crowd science and engineering concept and provide some answers about crowd cyber-system questions regarding crowd intelligence in logistic sector.
\end{abstract}

Keywords Bibliometric analysis, Crowd intelligence, Crowd logistics, Crowd cyber system, Sharing economy logistics

Paper type General review

\section{Introduction}

For more than 20 years, the sharing economy has been recognized as a mode of consumption based on the exchange of services and the sharing of under-exploited goods, exemplified by social media, mobile technologies, big data analytics and cloud computing or social, mobile, analytics and cloud (SMAC) solutions. Information technology (IT) is a key enabler of sharing practices and determines the development of new successful business models in the global economy (e.g. Airbnb, Uber) (Ocicka and Wieteska, 2017). IT makes the concept of sharing and its practices

(C) Laurence Saglietto. Published in International Journal of Crowd Science. Published by Emerald Publishing Limited. This article is published under the Creative Commons Attribution (CC BY 4.0) licence. Anyone may reproduce, distribute, translate and create derivative works of this article (for both commercial and non-commercial purposes), subject to full attribution to the original publication and authors. The full terms of this licence maybe seen at http://creativecommons.org/licences/by/4.0/ legalcode

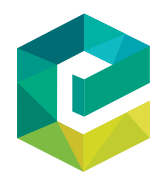

International Journal of Crowd 
IJCS
5,1

more accessible and flexible. IT promotes information sharing and business-to-business or B2B collaboration and improves supply chain processes. Online platforms allow the identification of appropriate individuals and businesses and potential exchanges, including information required for bookings and/or fee payments. For consumers, IT increases the efficiency and effectiveness of their trade activities, increases utilization rates and allows the re-circulation of goods while simultaneously reducing transaction costs and information asymmetries (Gansky, 2010; Belk, 2014; Taeihagh, 2017). Although the sharing economy has undergone a phasing in period, debate continues over how sharing modes should be classified, i.e. based on the related goods and services or on sectors. A sharing economy can be achieved among a few individuals or within a community or a crowd. In the domestic market, sharing practices are well established at both the individual and collective levels. They include practices based on horizontal networks and community participation and can transform lifestyles and working modes. The crowd phenomenon emerged alongside SMAC solutions. It is a particular aspect of the sharing economy in which economic activity is exercised through consumer-to-consumer (peer-to-peer) or businessto-consumer crowd involvement. Another aspect that continues to be debated is the economic model underpinning the sharing economy, i.e. the model that allows individuals and groups to share services or assets recognized as underutilized. When the sharing economy first emerged, exchanges were free of charge and anchored in the concrete social economy. Consumption is "responsive", it responds to a proven need. However, it incurs costs (Acquier et al., 2017) and generates benefits, as emphasized by the more current definition of the sharing economy, which is: "An economic system in which assets or services are shared between private individuals, either free or for a fee, typically by means of the Internet" (Oxford dictionary, 2019). The new relationships born out of the sharing economy have given rise to new forms of exchange. The economic network is tending towards an open, self-organized and ecological collaborative network, similar to an intelligent "digital business ecosystem" (Moore, 1996, 2003). In crowd science and engineering, this intelligent business ecosystem is described as the "crowd cyber system" (Chai et al., 2017; Liu et al., 2018). This community, which is composed of smart entities (individuals, enterprises, etc.), requires specific organization and logistics. Logistics are crucial for the optimization of unused or under-used assets and enables their pooling or sharing through digital platforms. The sharing economy has been recognized as a complex economic services activity some of which complexity is managed by sharing economy logistics in which the crowd is a determining component. It provides specific services to accomplish last-mile delivery.

Sharing economy logistics are involved in sharing across all parts of the logistics value chain. Its models are based on solving issues related to risk liability, insurance, transparency and workforce protection. For example, in the case of warehousing, the sharing economy allows shared utilization and billing in existing customer warehouses. According to the Brookings Institution, the current sharing economy is forecast to grow from US\$14bn in 2014 to US\$335bn in 2025 [1]. According to this estimate, sharing economy logistics will become increasingly significant with crowd logistics their central component. The term crowd logistics was coined to refer to the transfer of crowd work to the logistics sector. Crowd logistics is an emerging concept, involving ordinary people assuming the role of low-cost carriers. There is no consensus on the definition of crowd logistics, but Frehe et al. (2017, p. 77) define it as follows: "Crowd Logistics designates the outsourcing of logistics services to a mass of (not necessarily business) actors, whereby the coordination is supported by a technical platform, which is hosted and managed by a crowd logistics provider" [2].

In this context, the objective of the present research is to provide a quantitative analysis of the sharing economy logistics and crowd logistics academic literature. The following questions act as the common thread in our research: 
RQ1. How is the literature on sharing economy logistics and crowd logistics structured?

RQ2. What are the main trends in sharing economy logistics and crowd logistics?

RQ3. What are the options for future research?

The aim is to provide a comprehensive and precise understanding of the concept of sharing economy logistics and crowd logistics. We exploit rigorous bibliometric tools to provide a summary of the existing literature and contribute to the creation and accumulation of the knowledge on the sharing economy logistics and crowd logistics domain.

Specifically, Section 2 describes the bibliometric method, the step-wise research protocol and the software used for the bibliometric analysis. In Section 3, we present the results related to 85 selected articles published between 2007 and 2019. The structure of the literature is based on different units of analysis (publication year, subject area, categories and journals, authorship, bibliographical references). The bibliometric analysis (based on titles, keywords and abstracts) identifies the main trends in sharing economy logistics and crowd logistics. The main trends are organized around three clusters: Cluster 1 refers to the optimal allocation of costs, prices, distribution and supplier relationships; Cluster 2 corresponds to business related crowdsourcing and international industry practices; and Cluster 3 includes the impact of transport on last-mile delivery, crowdshipping and the environment. In Section 4, we discuss the following research trends: optimization of urban logistics problems, mobilization of crowd logistic for crowdsourcing business efficiency and shared mobility for last-mile delivery. Section 5 proposes some directions for future research in the context of the evolution from the organization of crowd logistics to the intelligence of the crowd and the complexities of crowd logistics such as understanding how the social crowd can be integrated into the logistics process. Section 6 concludes the paper.

Our results contribute to the notion of crowd science and engineering and are in line with the recent work on crowd cyber systems (Chai et al., 2017; Liu et al., 2018). This multidisciplinary framework (Li et al., 2019a, 2019b; Han et al., 2019) is based on several theories that include methods and tools able to capture the emergent concept of crowd cyber systems. Our research on sharing economy logistics and crowd logistics provides some answers to questions posed in the context of crowd cyber systems regarding crowd intelligence in the logistics sector.

\section{Research methodology}

Bibliometric analysis allows exhaustive and rigorous examination of all aspects related to publications on a particular topic (Okubo, 1997; Zupic and Čater, 2015; Gaviria-Marin et al., 2019). It uses a quantitative linguistic technique that consists of statistical and mathematical methods applied to sets of bibliographic references to the academic literature (Quoniam $e t$ al., 1993; Perrier et al., 2016). We use a step-wise bibliometric approach to describe and map the academic literature on sharing economy logistics and crowd logistics.

Our bibliometric research protocol draws on the work of David and Han (2004), Newbert (2007), Macpherson and Holt (2007) and Mishra (2018). Our method identifies a coherent and focused sample of publications on sharing economy logistics and crowd logistics. This strict protocol started with 112 articles and resulted in a final data set of 85 articles identified in a stepwise procedure.

- Step 1 - database. The focus was on articles included in the Business Source Complet, Emerald Publishing, Science Direct, Scopus and Springer databases. Their multidisciplinary approaches to in economics and business topics makes them 
IJCS

5,1

appropriate for our review. Business Source Complet indexes more than 1,320 peerreviewed journals from around the world, Emerald Publishing includes 360 journals, Science Direct 2,000, Scopus 21,500 and Springer 1,900 journals.

- Step 2 - topic choice. We ensured substantive relevance by requiring the term "sharing econom*" in the article titles, keywords or abstracts.

- Step 3-additional topics. Based on the definitions provided in the introduction, we checked for the inclusion in the articles of the terms "logistics" or "crowd logistics".

- Step 4-type of publication. The review was restricted to published peer-reviewed, academic articles published in international journals and in conference proceedings. For consistency, we restricted our choice to articles published in English, the most frequent language for research papers.

- Step 5 - type of content. We retained all academic articles and annual meetings proceedings with empirical and/or theoretical content (i.e. we excluded books and book chapters).

- Step 6-editorial choices. No filter and no specific period.

- Step 7 -coherence. We eliminated duplicate articles and incomplete citations. We applied several elimination criteria: diversity of knowledge bases proved a major source of duplication; we excluded articles with no or irrelevant abstracts and irrelevant articles (i.e. keywords unrelated to the topic).

- Step 8 -verification. We ensured substantive and empirical relevance by reading all remaining abstracts.

- Step 9 - consolidation. To ensure substantive context and empirical relevance, we read all the remaining articles in their entirety.

The results were are exported to Endnote bibliographic software, and the data were analyzed using Alceste software that proposes bibliometric analysis based on analysis of textual data (www.image-zafar.com/Logicieluk.html).

The analysis uses different basic bibliometric indicators: purely quantitative measures based on counts of bibliographic elements such as publication date, subject area, journal, authors, bibliographical references and measures for links between different bibliographic elements (co-publication and word co-occurrence based on word cartography and descending hierarchical classification - DHC).

The bibliometric analysis provided quantitative results that shed new light on scientific research into sharing economy logistics and crowd logistics.

\section{Results}

General results. The data collection (Steps 1 to 6 of the research protocol) identified 112 articles whose number was reduced to 85 after Steps 7 to 9 of the research protocol. The 85 articles involved 267 authors and 65 different peer-reviewed journals or annual meeting proceedings, between 2007 and June 2019.

\subsection{The structure of the literature on sharing economy logistics and crowd logistics}

3.1.1 Yearly numbers of publications. Time analysis indicates that since Jaržemskis's (2007) seminal article, the body of research on sharing economy logistics and crowd logistics has increased steadily to 2019, with a peak (32 publications) in 2018 (Figure 1).

Jaržemskis's article, which was published in the journal Transport, focuses on three of the most promising and relevant technical aspects of sharing economy logistics: strong 
cooperation with other companies in the same sector, within a logistics centre; container terminals/warehouses; and trailer and innovative transhipment equipment. These notions led to the idea of crowd logistics, which exploited a new type of collaboration and new social networks, providing economic, social and environmental benefits. The publications peak in 2018 is evidence of the greater academic interest in sharing economy logistics in the most recent years. It can be explained by the rise in digital sharing platforms that allow instant access to what is available, via online user networks. Individual and business users can obtain temporary access to an asset, service or skill owned by some other individual or organization, which, otherwise, would be underused. They include sharing of warehousing space, transport capacity, delivery methods, operational data and workers.

Thus, the interest in sharing economy logistics and crowd logistics, especially between 2016 and 2018, can be explained by various concurrent factors, including the concept of collaboration (collaborative economy, collaborative consumption, collaborative platforms), the rise of intermediation, processing of massive data and artificial intelligence (AI) to manage flows.

3.1.2 Subject areas and structure of the literature. The number of scientific publications is evidence of academic interest in a particular subject. Several scientific disciplines are contributing to work on sharing economy logistics and crowd logistics. To illustrate the variety of subject areas related to the 85 articles on sharing economy logistics and crowd logistics, we use the Scimago Journal and country rankings (www.scimagojr.com/). This international system covers all the databases we included in our research protocol. It makes it easier to identify the thematic orientation of the journals and conferences proceedings in our database and is dedicated to analysis, representation and retrieval and visualization of scientific information and is aimed at revealing its structure. It can offer a very intuitive image of the interconnection among different subject areas and subject area categories. The analysis shows that the most prolific fields working on sharing economy logistics and crowd logistics are business, management and accounting, followed by social science, engineering, computer science and decision sciences (Appendix). The dominant categories in order of importance are management science and operations Research followed by transportation and engineering (structural engineering, automotive engineering, mechanical engineering, etc.) (Appendix).

The indexing results suggest that research on sharing economy logistics and crowd logistics are multidisciplinary, which is supported by their publication in journals that publish more extensively on this topic.

3.1.3 The most productive journals. The number of peer-reviewed scientific papers published by a particular journal demonstrates the impact of publication in a leading scientific journal in the area of sharing economy logistics and crowd logistics. No one journal dominates, although there are several journals that have published a significant

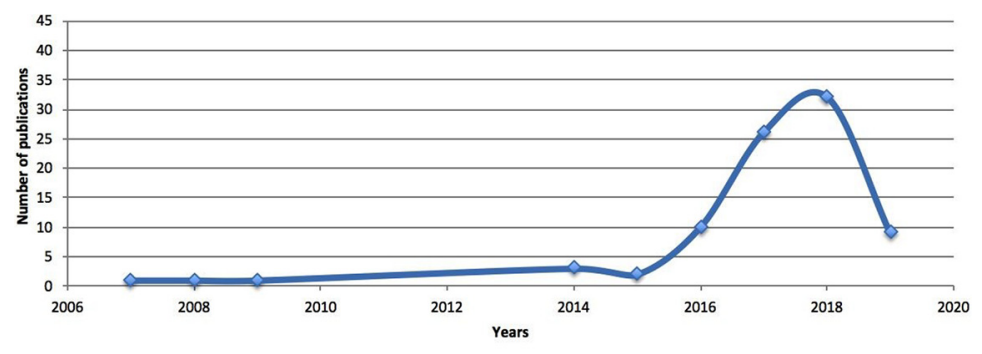

Figure 1.

Number of

Note: total of 85 articles 
IJCS
5,1

36

number of articles, while some have published only one article on sharing economy and crowd logistics (Table 1).

There is a new trend in transportation system logistics, aimed at providing more economically and environmentally beneficial alternatives to current practices, whose core concepts are represented by logistic-oriented practices related to infrastructure sharing, service integration and crowd planning. The sharing economy logistics and crowd logistics concepts have contributed to the emergence of a new freight transportation paradigm. Logistics sharing capacity assumes access to and sharing of operational capabilities, via the sharing of vehicles, vehicle capacity, warehousing space and infrastructure (Melo et al., 2019). The transport sector was the first to enter the sharing economy and to recognize the benefits to be derived from logistics centres for users and businesses (Jaržemskis, 2007; Yildiz and Savelsbergh, 2019). Here, the emphasis is on different types of urban transport logistics operations (Hensher, 2018; Janjevic and Ndiaye, 2017). For example, "Post 4.0" (Kunze, 2016; Kunze et al., 2016), "circle packing" (based on the crowd and the number of neighbours needed to manage parcel deliveries) (Akeb et al., 2018; Devari et al., 2017), "crowdshipping" (private drivers offering to make deliveries for multiple others, during routine trips - "last-mile delivery") (Behrend and Meisel, 2018; Ermagun and Stathopoulos, 2018; Gdowska et al., 2018; Punel and Stathopoulos, 2017; Punel et al., 2018; Serafini et al., 2018; Wang et al., 2016) and "crowd logistics" (deliveries enabled by exploiting excess passenger capacity on regular journeys) (Buldeo Rai et al., 2017; Wang et al., 2016).

3.1.4 Most prominent authors. The 85 articles involved 258 authors. There is a clear trend towards collaboration and co-authorship (Table 2): "The number of a paper's cosigners (or co-authors) is an indicator of co-operation at national or international level" (Okubo (1997, p. 25). Co-authorship analysis provides information on: scientific orientation and dynamism of the university and/or country, impact on the national and international communities and scientific networks. Note that only ten authors were responsible for more than one (i.e. 2) publication.

3.1.5 Analysis of the bibliographical references in the 85 articles. Analysis of the citations in the 85 articles highlights a common base (hard core) of articles and the theoretical underpinnings of the literature. According to Okubo (1997, p. 17) "citations are a measure of the overall impact of an article's influence, or that of its authors, on the scientific community; they are a complex socio-epistemological parameter which probably induces a quality

Table 1.

The most cited journals

\begin{tabular}{lc}
\hline Journals & Quantity \\
\hline Transportation Research Part E: Logistics and Transportation Review & 5 \\
International Journal of Contemporary Hospitality Management & 4 \\
Transportation Research Procedia & 4 \\
Journal of Business Logistics & 3 \\
Journal of Cleaner Production & 3 \\
Environmental Innovation and Societal Transitions & 2 \\
International Journal of Physical Distribution and Logistics Management & 2 \\
Logistics & 2 \\
MIS Quarterly Executive & 2 \\
Sustainability & 2 \\
Transport Policy & 2 \\
Transportation Research Part A: Policy and Practice & 2
\end{tabular}

Notes: Total of 85 articles. Only articles cited more than once appear in the table. For the full table, see Appendix 
factor, but this factor is neither equivalent to, nor unequivocally correlated with, scientific quality". Table 3 lists the most frequently cited authors and the main articles cited (founding article cited more than ten times).

\section{Sharing economy logistics}

\subsection{Linguistic analysis to identify sharing economy logistics and crowd logistics trends}

We used Alceste software to analyze the words in titles, keywords and abstracts for the 85 articles. "The co-occurrence of words indicator examines the frequency with which two given words ("co-words) in a particular field are used together. For each word, its cooccurrence with another word is analysed, along with its frequency" (Okubo, 1997, p. 30). The frequency of word associations is used to construct word clouds representing the major themes in the field under study and the relationships among them.

Alceste software allows a series of linguistic analyses (of titles, keywords and abstracts). First, it allows detailed analysis of the vocabulary in a corpus, to construct a dictionary of the words, their roots and their frequency. We obtained 17,690 forms, including 3,266 words, which represent a rich vocabulary of $87 \%$ of unique words. Second, successive fractionation splits the text up into homogeneous segments containing a certain number of reduced words forms (e.g. shar*=share, sharing, shared...). Third, we conducted a hierarchical classification of these segments, based on locating the strongest oppositions (in our case, words with at least 50 occurrences - Figure 2). The results of the analyses were sorted according to relevance, and several graphic representations (word cloud, DHC) were constructed. The size of the words in the word cloud is proportional to the number of their occurrences (greater frequency means larger font size). The word sets are based on colours of the words and constitute a first step towards a publications classification.

This representation shows the links between sharing economy logistics and platformbased collaborative consumption. The sharing economy logistics business model centres on delivery services that include crowd logistics and support sustainability.

Because it is not possible to represent all of the data in a unique multidimensional word cloud, Alceste software proposes a variety of methods based on multidimensional analysis techniques, including DHC. DHC involves successive fractionations of the text and representative extracts, based on appearance in text segments of the same terms. Each homogeneous thematic class is examined on the basis of a "profile". For each profile, Alceste identifies a list of the most significant words and sentences. By calculating the $\chi^{2}$, we can determine strong or weak belonging of a word to a class: the $\chi^{2}$ highlights the most relevant terms for a given class and the most influential references per cluster (Figure 3). This method allows extraction of clusters of meaning, based on the most significant words and

\begin{tabular}{lc}
\hline No. of authors per article & Quantity \\
\hline 1 author & 14 \\
2 authors & 19 \\
3 authors & 23 \\
4 authors & 13 \\
5 authors & 7 \\
6 authors & 3 \\
7 authors & 4 \\
authors & 2
\end{tabular}

Note: Total of 85 articles

Table 2.

Distribution of articles by author numbers 


\begin{tabular}{lcl}
\hline Authors & Count & Major articles \\
\hline Tong Y.X & 36 & •Tong, Y.X., She, J.Y., Ding, B.L., Wang, L.B., Chen, L., 2016. Online
\end{tabular}

$\begin{array}{ll}\text { Tong Y.X } & 36 \\ \text { Chen, L } & 35\end{array}$

She, J.Y 18

\section{8}

Mladenow A.

Strauss C.

Bauer C

Belk R

Marrucci E.

Gatta v

Macharis C.

Verlinde S.

Buldeo Rai H

Botsman R

Rogers R

Lin J.

Kafle N.

Zou B

Cohen B.

Kietzmann J

Agatz N.

Wang X.

Arslan A

Rouquet A.

Carbone V.

Roussat C

Mckinnon A

Browne M

Table 3 .
The top ten most

cited authors and the major articles

mobile micro-task allocation in spatial crowdsourcing. Proc. 32nd

IEEE Int. Conf. on Data Engineering, pp. 49-60

-She, J.Y., Tong, Y.X., Chen, L., Cao, C., 2015. Conflict-aware eventparticipant arrangement. Proc. 31st IEEE Int. Conf. on Data

Engineering, pp. 735-746
-Mladenow, A., Bauer, C. and Strauss, C. 2016. Crowd logistics': the contribution of social crowds in logistics activities, International Journal of Web Information Systems, 12(3), pp. 379-396

-Mladenow, A., Bauer, C., and Strauss, C. 2015. Collaborative Shopping with the Crowd. In Cooperative Design, Visualization, and Engineering. LNCS. Springer International Publishing. 162-169

-Belk, R. 2014. You Are What You Can Access: Sharing and Collaborative Consumption Online. Journal of Business Research 67 (8): 1595-600

-Marcucci, E., Gatta, V., Scaccia, L., 2015. Urban freight, parking and pricing policies: An evaluation from a transport providers' perspective, Transport. Research part A: Politic and Practices., 74, pp. 239-249

-Gatta, V.; Marcucci, E. Urban freight transport and policy changes: Improving decision makers' awareness via an agent-specific approach. Transport policy, 36, 248-252

-Macharis, C., Kin, B., 2017. The 4 A's of sustainable city distribution: innovative solutions and challenges ahead. International Journal of Sustainable Transport. 11, 59-71

-Rai, H.B., Verlinde, S., Merckx, J., Macharis, C., 2017. Crowd logistics: an opportunity for more sustainable urban freight transport? Eur. Transp. Res. Rev. 9

-Botsman, R., Rogers, R., 2010. What's Mine is Yours. The Rise of Collaborative Consumption, Harper Business, New York, NY -Kafle, N., Zou, B., and Lin, J. 2017. Design and modeling of a crowdsource-enabled system for urban parcel relay and delivery. Transportation Research Part B: Methodological, 99, pp. 62-82 -Cohen, B., and Kietzmann, J. 2014. Ride On! Mobility Business Models for the Sharing Economy. Organization and Environment 27 (3): 279-96

-Agatz, N., Erera, A., Savelsbergh, M., Wang, X., 2012. Optimization for dynamic ride-sharing: a review. Eur. J. Oper. Res. 223, 295-303

-Arslan, A., Agatz, N., Kroon, L., Zuidwijk, R., 2016. Crowdsourced Delivery - A Pickup and Delivery Problem with ad-hoc Drivers. ERIM Report Series Reference

-Furuhata, M., Dessouky, M., Ordóñez, F., Brunet, M.-E., Wang, X., Koenig, S., 2013. Ridesharing: the state-of-the-art and future directions. Transportation Research Part B: Methodological, 57, 28-46 -Carbone, V., Rouquet, A., and Roussat, C. 2015. Carried Away by the Crowd: What Types of Logistics Characterise the Collaborative Economy?, Paper presented at the 1st International Workshop on Sharing Economy, June 4-5, Utrecht

-McKinnon, A., Browne, M., Whiteing, A., 2015. Green Logistics: Improving the Environmental Sustainability of Logistics. Kogan Page Publishers

(continued) 


\begin{tabular}{|c|c|c|c|}
\hline Authors & Count & Major articles & \\
\hline Prosperio D. & 14 & -Zervas, G., Proserpio, D. and Byers, J. 2015, The Rise of the Sharing & logistics \\
\hline Zervas G. & 12 & Economy: Estimating the Impact of Airbnb on the Hotel Industry, & \\
\hline Buyers J & 11 & School of Management, Boston University, Boston, MA & \\
\hline Archetti C. & 13 & •Archetti, C., Savelsbergh, M., Speranza, M.G., 2016. The Vehicle & \\
\hline Savelsbergh M. & 11 & Routing Problem with Occasional Drivers. European Journal of & \\
\hline Speranza M & 12 & Operational Research 254.(2), 472-480 & 39 \\
\hline Howe J & 12 & $\begin{array}{l}\text { •Howe, J. 200, “The rise of crowdsourcing”, Wired Magazine, } 14 \text { (6), } \\
\text { pp. } 1-5\end{array}$ & \\
\hline Mehmann & 11 & •Mehmann, J., Frehe, V., Teuteberg, F., 2015. Crowd logistics a & \\
\hline Frehe V. & 11 & literature review and maturity model. in Innovations and Strategies & \\
\hline Teuteberg & 11 & $\begin{array}{l}\text { for Logistics and Supply Chains: Technologies, Business Models and } \\
\text { Risk Management. Proceedings of the Hamburg International }\end{array}$ & \\
\hline & & Conference of Logistics (HICL), Vol. 20 (pp. 117-145) & Table 3. \\
\hline
\end{tabular}

sentences that represent the dominant ideas and themes in the corpus. It identifies the main trends in sharing economy logistics and crowd logistics.

The three clusters discussed above encompass the main topics and dimensions revealed as decisive for an understanding of sharing economy logistics and crowd logistics. Analysis of these three thematic classes relies on a specific vocabulary:

(1) Cluster 1 (red-27\%) refers to optimal allocations of costs, prices, distribution and supplier relationships. This is a multidisciplinary theme in terms of publication media and extends over more than ten years. The main, but not the only, authors and articles with significant representation in the cluster are: Karabati and Saym (2008), Wallenburg (2009), Chen et al. (2014), Beliën et al. (2017), Guiliang et al. (2017), Kong et al. (2018) and Gan et al. (2018). The starting point of this research was supply chain informational coordination incorporating buyers' expectations within a sharing economy. Proactive enhancement of the links to logistics service providers would seem to be a driver of urban customer loyalty in the sharing economy. Over time, the central theme has become optimization of trajectory-aware coordinated urban crowdsourcing of deliveries.

(2) Cluster 2 (blue - 49\%) refers to businesses using crowdsourcing and international industry practices. In this cluster, the main, but not the only, authors and articles with significant representation in the cluster are: Mladenow et al. (2016), Frehe et al. (2017), Taeihagh (2017), Williams and Horodnic (2017), Wang et al. (2018), Bachnik and Szumniak-Samolej (2018), Boxall et al. (2018), Chen et al. (2018), Zhang et al. (2018) and Volgger et al. (2018). Since 2016, research in this area has focused on crowd logistics. The firms in this cluster are interested in the contribution of the social crowd to logistics activities and involve evaluation of crowd logistics business models that use members of the public to achieve last-mile delivery. This consumer participation in logistics service is crucial and depends on individuals' cognitions and affects.

(3) Cluster 3 (green - 24\%) relates to the impact on the environment of transport related to last-mile delivery and crowdshipping. The main, but not the only, authors and articles with significant representation in the cluster are: Kunze (2016), Devari et al. (2017), Buldeo Rai et al. (2018), Qi et al. (2018), Gatta et al. (2019), Melo et al. (2019) and Martin et al. (2019). Research in this cluster emphasizes the environmental potential of collaborative consumption and stakeholder analysis of crowd logistics platforms in different European countries. Shared mobility, involving the crowd in last-mile delivery, relies on public transport and sustainable city logistics. 


\section{IJCS \\ 5,1}

Figure 2.

Word cloud and frequency of representative words in research on sharing economy logistics and crowd logistics

\section{Citation greater than 50}

Shar* (195), Logistic* (192), Econom* (160), Model (101), Research (95), Deliver* (93), Crowd* (85), Service* (81), Sustain* (68), Platform (68), Transport* (68), Cost* (67), Business (53), Collabor* (53)

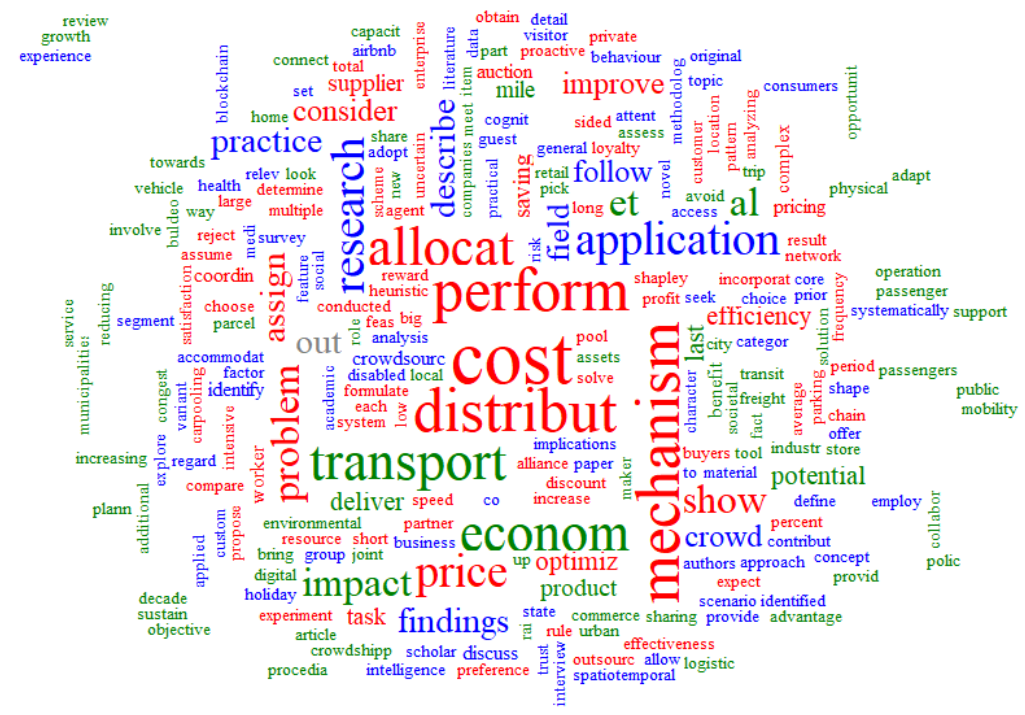

Note: Total of articles : 85

Each of these three clusters reveals trends that are presented and discussed in the succeeding sections.

\section{Major research trends in sharing economy logistics and crowd logistics 4.1 Trend 1. Optimization of urban logistics problems}

Cluster 1 includes research on urban logistics and real problems, based on optimal allocation of costs, prices and distribution models. Several articles focus on decision protocols, planning and distribution models and optimization processes. For example, one of the solutions suggested to achieve higher system profitability and save on agents' costs is for the platform to leverage public parking spaces. The solution is feasible, but has yet to be incorporated into a system and verified in real-world application (Kong et al., 2018). Other articles highlight how the rapid growth of logistics distribution is revealing an imperfect logistics distribution network infrastructure (Li et al., 2018) and high distribution costs (Gan et al., 2018). The main works propose new intelligent solutions to these urban problems, such as collaborative shipping to reduce fuel and emissions costs (Beliën et al., 2017), shared warehousing to maximize space (He and $\mathrm{Gu}, 2018$ ) and coordination in single-supplier/multiple-buyer supply chains (Karabati and Saym, 2008). These solutions are proving efficient and are increasing profitability (Kong et al., 2018; Karabati and Saym, 2008). 


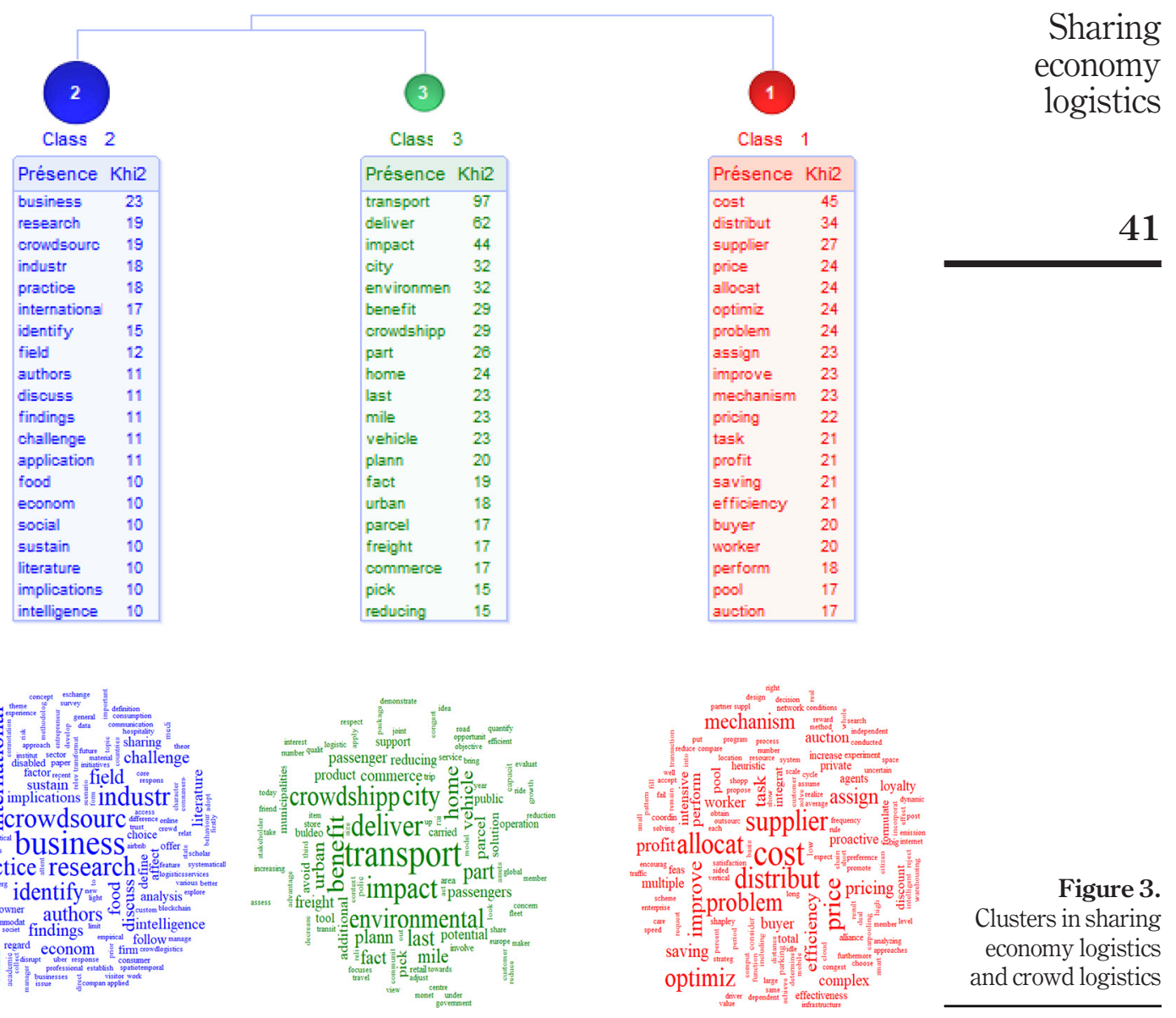

Several papers provide analyses of worker trajectories within a platform-enabled coordinated task assignment approach (Chen et al., 2014). This strand of work looks at detour optimization to allow the worker to complete his/ser assigned tasks (Chen et al., 2014) and customers' shopping behaviour, which affects the customer's delivery logistics preferences (high speed, low cost, etc). (Gan et al., 2018). Other problems are being tackled by application of IT and big data, which are able to capture customers' logistics needs by analyzing their distribution logistics preferences and are promoting integration and optimization of logistical resources (Zhai and Du, 2017), improving participant satisfaction Gan et al. (2018) and allowing more efficient performance at lower cost, all of which increase customer loyalty (Gkatzelis et al., 2016; Wallenburg, 2009). In the case of simple outsourced services and short contracting periods, customer loyalty depends only on costs (Wallenburg, 2009). Crowd logistics have the potential to improve city logistics; however, it is not obvious, from an economic, societal and environmental perspective, how the crowd could best be exploited for the performance of logistics services. 


\section{IJCS \\ 5,1}

\subsection{Trend 2. Mobilization of crowd logistic for efficient business crowdsourcing}

In Cluster 2, business research focuses on the crowd and business models (Mehmann et al., 2015; Frehe et al., 2017). As the sharing economy has evolved, it has spread to multiple economic sectors across the world. Sharing is defined as the simultaneous or sequential use, by several people, of an object (e.g. a car), a space (e.g. a living room) or an intangible element (e.g. an identity) (Rudmin, 2016). Initially, sharing was related to achieving more sustainable use of resources (Pottinger, 2018; Mishra, 2018; Geissinger et al., 2019); it has become significant for business practices, logistics and supply chain management. Most authors distinguish between the sharing economy and crowdsourcing (Taeihagh, 2017; Tong et al., 2017), although both involve use of IT, trust in exchanges and reputation systems. They tend to be distinguished by their use of these IT systems to resolve specific problems (Taeihagh, 2017). Some works focus on different sharing best practice and the factors involved in successful development of logistics and supply chain management (Zinn and Goldsby, 2017). Examples include analysis of opportunities for social crowd integration in logistics processes (Mladenow et al., 2016) and the types of services proposed by crowd logistics (Carbone et al., 2017, 2018). Some recent food consumption and food distribution initiatives are related to sustainable consumption, the sharing economy and collaborative consumption. This stream of work indicates that, in the area of consumer durables, individual consumers seem to be recognizing the value to be derived from more responsible behaviour and collaborative economy projects (Ukolov et al., 2016; Bachnik and Szumniak-Samolej, 2018). Online platforms that connect and facilitate transactions between the owners of underutilized assets and users who will pay to use these assets for a limited time are disrupting many sectors (Zhang et al., 2018). Traditional businesses facing this new competition are implementing new strategies (Ukolov et al., 2016; Ocicka and Wieteska, 2017). Social exchanges involve aspects such as user motivation and attitude, consumption experience and cultural usage of the sharing economy. Several studies suggest that the link between human intelligence and the choice of modes of access based on social exchanges can be explained by individual and institutional consumers' increased social trust (Wang et al., 2018; Aspara and Wittkowski, 2018). This strand of work is complemented by studies of crowd intelligence platforms (Li et al., 2017). Planners and decision-makers should consult with one another and take account of the needs of socially excluded groups when deciding how to regulate shared economy enterprises. Broader social inclusion rather than the regulation of peer platforms should be the primary focus of legislation (Boxall et al., 2018).

\subsection{Trend 3. Shared mobility for last-mile delivery}

In Cluster 3, shared mobility for last-mile delivery is the source of numerous innovative solutions that reduce environmental impact. There are two main strands of research in the field of transport. The first is related to shared mobility for last-mile delivery. Parcel delivery, a major outcome of the growth of e-commerce, is challenging urban logistics (Akeb et al., 2018) and highlighting the need to transform current consumption patterns to achieve more sustainable practices. The research proposes several solutions related to last-mile delivery, based on crowd-tasking models and scalable solutions. In the context of urban logistics, lastmile delivery from the warehouse to the consumer's home has become particularly complex. It requires elaborate planning and scheduling to minimize overall transport costs and environmental pollution, but can result in a failed delivery if the consumer is not at home. Several shared mobility solutions have been proposed to address this problem (Qi et al., 2018), including Post 4.0 using ground drones (Kunze, 2016), mobile crowd-tasking involving a large pool of citizen workers to achieve last-mile delivery (Wang et al., 2016), crowdsourcing of lastmile deliveries of online orders by exploiting the social networks of retail store customers or reception of deliveries by friends and neighbours. These solutions reduce emissions and ensure 
speedy and reliable delivery (Devari et al., 2017; Akeb et al., 2018). Peer-to-peer product sharing platforms integrated with package drop-off/pick-up services in urban districts are also reducing the impact on the environment (Martin et al., 2019).

The second strand of work focuses on public transport-based crowdshipping for sustainable city logistics (Sampaio et al., 2017). This research is aimed at understanding and evaluating the environmental and economic impacts of crowdshipping platforms in urban areas (Gdowska et al., 2018). Environmentally friendly crowdshipping is based on use of mass transit city networks and customers/crowdshippers picking up/dropping off goods using automated parcel lockers, located in or near transit stations. Crowdshippers include individuals who use the transit network for other activities (e.g. travel to and from work), which avoids additional trips (Serafini et al., 2018; Gatta et al., 2019). Crowdshipping platforms match supplies to requests to planned trips by community members (Behrend and Meisel, 2018). Crowd logistics allow more sustainable urban freight transport. Also, the emergence of smart transport is highlighting opportunities to relieve road congestion through use of collaborative and connected mobility models (Hensher, 2018). Crowd logistics envisages delivery operations using excess passenger capacity on scheduled routes; this has the potential to provide economic, social and environmental benefits (Buldeo Rai et al., 2017, 2018). Crowd logistics offers an alternative to traditional home deliveries by parcel companies and is considered more sustainable. The rationale underlying crowd logistics are that parcels and passengers are co-transported on a passenger journey. It relies on opportunities to monetize the already existing resources rather than creating additional infrastructure to try to meet demand (Melo et al., 2019).

Bibliometric analysis allows an overview of the development of the field and identifies research trends. The crowd allows optimization of urban logistics, increases crowdsourcing business efficiency and exploits shared mobility for last-mile delivery. But, there are still questions. How the crowd can be mobilized, organized and optimized to exploit their travel time and travel mode? How appreciate their diversity, their behaviour and their intelligence?

\section{Discussion}

\subsection{The emergence of a crowd cyber system}

We have shown that sharing economy logistics and crowd logistics are undergoing a continuous evolutionary process, which is highlighting crowd cyber systems as a promising research topic. Li et al. (2018, p. 343) see this evolution as "a golden period towards smart logistics" while underlining that the social crowd could be integrated into logistical processes that include international industry practices and last-mile delivery.

We have seen that logistics (transportation, warehousing, support services, cargo handling, etc). has evolved from being a work management tool to becoming a managerial approach (Zhai and Du, 2017), involving the coordination of goods and/or information deliveries to the right person, in the right place and at the right time (Mladenow et al., 2016). In the delivery race, last-mile delivery is the most cost-intensive part of the transport chain, from both a financial and an ecological point of view (i.e. in terms of greenhouse gas emissions). In this case, crowd logistics allow shared activities that enhance flows of information and goods (Mladenow et al., 2016). Crowd logistics services refer to the outsourcing of logistics services to a mass of actors and to categories such as personal transport, freight transport and purchase and delivery services (combination of e-commerce, food shopping and deliveries). In the first two cases, the crowd is both the carrier and the beneficiary. The crowd logistics company acts as the mediator. In the third case, crowd logistics are an alternative to drones used for same-day delivery (Kunze, 2016). More research is needed on the returns to investment. Indeed, the research tends either to ignore the economic benefits or discuss them only briefly and little is known about the long-term 
IJCS
5,1

profitability and the risks involved in crowd logistics. This is a research direction where more work is needed.

Coordination of the logistics services outsourced to the crowd is supported by technical platforms, which are hosted and managed by crowd logistics providers and accessed via mobile apps, computer software or websites (Frehe et al., 2017). These technical platforms are used, primarily, as communication media and can be accessed in multiple ways using SMAC solutions. They use advanced technologies to coordinate supply and demand for transport services and to connect shippers to drivers. Crowd logistics platforms allow resources matching (Mladenow et al., 2016), operations management (route planning, driver monitoring Punel and Stathopoulos, 2017), higher-quality services (Buldeo Rai et al., 2018) and risk control (Mehmann et al., 2015). Crowd logistics platforms connect Web-based industries within an industrial eco-structure (Chai et al., 2017). This cyber-crowd system is enabled by a set of intelligent agents guided by the joint optimization of logistics operations. This network of intelligent agents is coordinated by the platform, which acts as an e-intermediary. Platforms are offering crowd management competence via Web media and resource utilization and business process management algorithms. They are allowing management of the crowd's intelligent transactions (supply and demand) and enabling dynamic pricing.

Each of the intelligent agents in the crowd cyber system has a particular role, which allows this eco-structure to adapt transactions to ongoing changes: "Transaction efficiency is the main inducement to the evolution of ecostructure" (Chai et al., 2017, p. 5). To adapt to variations in their environment, intelligent agents can implement collective strategies.

Therefore, a study of the crowd cyber system requires systemic analysis of the network connectivity among intelligent agents to assess the value they create (Li et al., 2019a, 2019 b). Measuring both profitability and risk is not straightforward; account needs to be taken of operating costs, customer availability, transaction costs related to transparent information and optimization models. The pricing model will reflect the crowd cyber system base value price for a set of intelligent agents, i.e. the margins related to the services delivered. The literature does not clarify how platforms create value. Crowd logistics involved private consumers, a few professional consumers and a customer network (Frehe et al., 2017; Li et al., 2017) and offers resources either for free (private individuals' resources e.g. free carsharing) or for a fee (crowdshipping) (Serafini et al., 2018). Crowd logistics are confined to specific regions or cities and are increasing competition and changing the behaviours of residents and attitudes to traffic problems. There are no national- or international-wide services in place, but they represent opportunities for firms. The proposed legislation, the transport infrastructures and the political constraints on crowd logistics need more in-depth investigation. Finally, in an urban context, transport logistics involves the public transport network (metro, buses, etc). to make last-mile delivery more efficient and reduce transport costs and emissions (Bubner et al., 2014). It should enable the ultimate environment-friendly service. Similar to most crowdsourced activities, the network of carriers and customers is an essential component. The service requires a critical mass, which might require incentives. Marketing research has investigated the need to implement mechanisms that take account of the motivation, availability, remuneration, satisfaction and intelligence of the crowd. Most current research proposes frameworks, models and algorithms for a better theoretical understanding of how the social crowd can be integrated into logistics processes. Some studies propose several solutions to enhance last-mile delivery, based on crowdtasking models and scalable solutions; in urban logistics, last-mile delivery from warehouse to consumer is increasingly complex. The inclusion of customers in these logistics processes could reduce transportation costs, $\mathrm{CO}_{2}$ emissions and traffic congestion, but crowdshipping, based on scheduled transport, will require a high level of involvement from the crowd logistics and a better understanding of the intelligence of the crowd. 
5.2 Crowd intelligence - the cornerstone of the crowd cyber system

Crowd intelligence emerges from the collective intelligence efforts (and different levels of expertise and dedication) of the crowd of autonomous individuals, organized in online networks and motivated to conduct transportation, services and computational tasks within the sharing economy. The theory of crowd intelligence or crowd wisdom was popularized by James Surowiecki (2004) who suggested that more effective problem perception and resolution can be achieved by a crowd compared to individual members acting alone. However, not all crowds are wise. Crowds have statistical evaluation power that is useful in logistics flow management. The crowd has knowledge and is capable of coordination and cooperation. Several studies try to understand the circumstances, which allow crowd wisdom to take effect. Crowds are defined by a diversity of opinion, independence, decentralization and aggregation. The crowd is composed of people from different backgrounds, with different ideas; the resulting crowd wisdom comes from the combination of ideas and knowledge. There are some mechanisms in place to translate private judgements into a collective decision. Diversity introduces corrective factors into statistical estimates. According to Surowiecki (2004, p. 29), "Diversity helps because it actually adds perspectives that would otherwise be absent and because it takes away, or at least weakens, some of the destructive characteristics of group decision making".

Thus, the wisdom of the crowd is not a philosophical entity, but rather a mathematical and statistical phenomenon that is aligned to Li et al.'s (2017, p. 17) view that "the crowd intelligence system interweaves crowd and machine capabilities seamlessly to address challenging computational problems". In this context, the crowd is no longer just a network agent/carrier or a user; it becomes a solutions creator that allows the creation of value. There are several reasons why the crowd can fulfil this role. Customers become contributors because of social motivation: priority is given to the process of exchanges among individuals, interpersonal aspects and consumer awareness of sustainability issues (Li et al.,2017). There is the possibility of financial gain from reduced transport costs, reduced prices and faster delivery. This research stream examines the effectiveness of the crowd organization because, in crowd logistics, the individuals involved are a priori unknown, are highly autonomous and may behave unpredictably. This unpredictable behaviour is explained in the crowd intelligence theory as informational effects. For example, when individuals lack information, they tend to imitate. They conform to whoever seems to "know", and the result can be positive or negative depending on whether the leader is right or wrong. Similarly, to safeguard their reputation, individuals may endorse the point of view of the majority. Several studies (Hadzikadic and Sun, 2010) provide simulations that consider the continuity in decision-making, the complexity of the world and the rapid evolution of individual interactions, irrational individuals and learning capacity to make individuals and crowds "smarter" over time.

Thus, "the crowd intelligence therein has great potential to explore beyond those from individual entities" (Wang et al., 2019, p. 25). Understanding how the crowd is organized and appreciating its diversity, behaviours and intelligence are all topics requiring further research.

So, how can individuals with different backgrounds and skills be organized to generate efficiency and persistent crowd intelligence? Coordination involves deciding which choices to consider based on an assessment of the other choices. The most promising approach, after the game theory and various optimization models, would seem to be machine learning, which takes account of the tacit conventions among the members of the crowd. According to Li Y (2019, p. 168), "it is of crucial importance to study how such smart entities interact with each other, to understand their decision-making process, to analyze how they influence each other and the impact of such interactions on the entire crowd intelligence networks". Investigating how information propagates within a crowd network could be informative for 


\section{IJCS \\ 5,1}

the design of efficient and effective resource allocation mechanisms, crowd intelligence network management approaches and measures of social welfare.

So, how can we capture the patterns of crowd intelligence and their mechanisms, in different scenarios, to design incentives and operational methods to best realize the crowd intelligence? According to Liu et al. (2018, p. 2) "in the crowd cyber system, the motivation and incentive of different intelligent agents are distinct. For individuals, they try to maximize their utility. For enterprises, they pursue higher profit. For governments, they need to take the welfare of the whole economy into consideration". Although financial incentives can be effective, reputation is also important. Other forms of incentives should be investigated in future research. Motivation and incentives are fundamental for the formation of a crowd network.

How should subtasks be distributed and outcomes aggregated? We need to know how to assess, control and guarantee the quality of the work, how to handle the potential risks related to the distribution of responsibilities, privacy issues, additional costs, delivery delays and security issues. It has been suggested that AI could enable interaction among the smart entities in the crowd cyber system. On online community platforms, AI enables knowledge sharing and knowledge management among individuals involved in large-scale collaborations. Finally, the link between AI and the internet of things could facilitate the management of crowd intelligence because crowd logistics is related to the idea of the physical internet. According to Buldeo Rai et al. (2017 p. 2), "The idea, is to encapsulate physical objects in modular packets and containers of which the header contains all information required for identifying the packet. These packets and containers are then routed as efficiently as possible so that it absorbs spare capacity in transport systems, ensuring that they get to their destination in time, regardless of the route followed".

Therefore, digitalization, analysis of big data and AI could connect cyber physical production systems and the crowd cyber system to optimize, control and predict the behaviour of all the systems involved in the sharing economy.

We have shown that crowd intelligence is becoming critical for an intelligent logistics ecosystem based on big data. The crowd cyber system is a major and growing multidisciplinary concept. It is both interesting and complex to analyze because of the multiplicity of approaches that could be used. The disciplines of business management, psychology, economics and computational intelligence are all conducting research in this area, based on different theories, approaches and tools such as collective intelligence, decision-making, cognition, AI, etc. Scientists, business people and computer programmers are all interested in this area. Big data is an important innovation and is influencing many areas of our global society (Chen, 2019). We need a systemic approach to digitalization of supply chains based on the crowd cyber system that links people, products, platforms and the crowd. The information contained in each digital technology is combined to provide an overall understanding of the intelligent digital ecosystem. This is the first step towards achieving Logistics 4.0 to support industry 4.0. Logistics 4.0 focuses on integrating within a network the most advanced information and communication solutions to ensure system interoperability and real-time communication (Bayarçelik and Bumin Doyduk, 2020), e.g. to enable last-mile delivery.

\section{Conclusion}

The purpose of this paper was to provide a systematic review of the rapidly evolving concepts of sharing economy logistics and crowd logistics. We proposed a structured approach to the body of work on this area. We conducted bibliometric analysis of 85 articles (academic papers and conference proceedings) included in five databases, during the time period 2007-2019, using lexical analysis tools and Alceste software. Bibliometric analysis is a scientific synthesis method. It allows extensive coverage of the literature and enables the 
sorting of relevant articles based on some common features, to identify the main topics and emerging fields. The scientific synthesis method is generalizable to other areas. We used it to address the following research questions:

\section{RQ1. How is the literature on sharing economy logistics and crowd logistics structured?}

A 1 . The study shows that this is an interdisciplinary subject, with contributions from business, management and accounting, social sciences, engineering, computer science and decision sciences. We found that the dominant categories are management science and operations research followed by transportation and engineering. Research in the field is at different stages in relation to understanding, modelling and practice. The increased interest in sharing economy logistics and crowd logistics between 2016 and 2019 can be explained by popularity of the idea of collaboration (collaborative economy, collaborative consumption, collaborative platforms) and the growth of intermediation, massive data processing and AI in the management of flows.

\section{RQ2. What are the main trends in sharing economy logistics and crowd logistics?}

A 2. The lexical analysis, which used Alceste software, highlighted three clusters. Cluster 1 refers to the optimal allocation of costs, prices, distribution and supplier relationships. Cluster 2 includes business and crowdsourcing and international industrial practices. Cluster 3 is related to transport and last-mile delivery, crowdshipping and environmental impact. Each of the three clusters revealed a research trend, which we presented and discussed. Trend 1 shows that, beyond collaboration, the success of sharing economy logistics requires optimization of urban logistics problems. Trend 2, international industry practices, depends on crowd logistics for efficient crowdsourcing business. Trend 3 emphasizes that share mobility for last-mile delivery is a source of performance that is generating innovative solutions to environmental impacts.

\section{RQ3. What are the future research options?}

A 3. Common to these three trends is that they highlight that sharing economy logistics and crowd logistics are continuous evolutionary processes. More research would provide a better understanding of crowd cyber systems and crowd intelligence and their integration into new logistics models. Crowd logistics is based on the concept of the sharing economy and the services it provides such as outsourcing of logistics services to a mass of actors, coordinated by various technical platforms. These platforms take account of crowd logistics intelligence to enable improved information sharing and optimization of last-mile delivery by the crowd, which makes the crowd cyber system essential for Logistics 4.0.

The asterisks indicate that the paper is one of the 85 articles analyzed.

\section{Notes}

1. https://logistics.apacciooutlook.com/cxoinsights/the-sharing-economy-on-ondemand-andlastmile-delivery-platforms-the-role-and-effect-nwid-4965.html

2. The definition proposed by (Buldeo Rai et al. 2017, p. 2) is: "Crowd logistics alternatively termed crowdshipping, crowdsourced delivery, cargo hitching or collaborative logistics is presented as a promising concept as it encourages passengers to use their spare carrying capacity on cars, bikes, buses and planes to carry parcels for other people CL uses the excess capacity on premeditated trips that already take place to make deliveries leading to maximisation of logistics efficiency and reduction of emissions and traffic". 


\section{IJCS \\ 5,1}

\section{References}

Acquier, A., Daudigeos, T. and Pinkse, J. (2017), "Promises and paradoxes of the sharing economy: an organizing framework", Technological Forecasting and Social Change, Vol. 125, pp. 1-10.

Akeb, H., Moncef, B. and Durand, B. (2018), "Building a collaborative solution in dense urban city settings to enhance parcel delivery: an effective crowd model in Paris", Transportation Research Part E: Logistics and Transportation Review, Vol.119, pp. 223-233.

Aspara, J. and Wittkowski, K. (2018), "Sharing-dominant logic? Quantifying the association between consumer intelligence and choice of social access modes", Journal of Consumer Research, Vol. 46 No. 2, pp. 201-222.

Bachnik, K. and Szumniak-Samolej, J. (2018), "Social initiatives in food consumption and distribution as part of sustainable consumption and sharing economy", Journal of Entrepreneurship, Management and Innovation, Vol. 14 No. 2, pp. 101-122.

Bayarçelik, E. and Bumin Doyduk, H. (2020), "Digitalization of business logistics activities and future directions", in Hacioglu, U. (Ed.), Digital Business Strategies in Blockchain Ecosystems. Contributions to Management Science, Springer, Cham, doi: 10.1007/978-3-030-29739-8_10.

Behrend, M. and Meisel, F. (2018), "The integration of item-sharing and crowdshipping: can collaborative consumption be pushed by delivering through the crowd?", Transportation Research Part B: Methodological, Vol. 111, pp. 227-243.

Beliën, J. Boute, R. Creemers, S. DE Bruecker, P. Gijsbrechts, J. Padilla Tinoco, S. and Verheyen, W. (2017), "Collaborative shipping: logistics in the sharing economy", ORMS Today, pp. 20-23.

Belk, R. (2014), "You are what you can access: sharing and collaborative consumption online", Journal of Business Research, Vol. 67 No. 8, pp. 1595-1600.

Boxall, K., Nyanjom, J. and Slaven, J. (2018), "Disability, hospitality and the new sharing economy", International Journal of Contemporary Hospitality Management, Vol. 30, pp. 539-556.

Bubner, N., Helbig, R. and Jeske, M. (2014), "Logistics trend radar. Delivering insight today. Creating value tomorrow!", available at: www.dhl.com/content/dam/downloads/g0/about_us/logistics_insights/DHL_Logistics-TrendRadar_2014.pdf

Buldeo Rai, H., Verlinde, S. and Macharis, C. (2018), "How are logistics service providers adapting to omnichannel retail?”, IFAC-PapersOnLine, Vol. 51, pp. 588-593.

Buldeo Rai, H., Verlinde, S. and Macharis, C. (2018), "Shipping outside the box. Environmental impact and stakeholder analysis of a crowd logistics platform in Belgium", Journal of Cleaner Production, Vol. 202, pp. 806-816.

Buldeo Rai, H., Verlinde, S., Merckx, J. and Macharis, C. (2017), "Crowd logistics: an opportunity for more sustainable urban freight transport?", European Transport Research Review, Vol. 9, pp. 1-1-13.

Carbone, V., Rouquet, A. and Roussat, C. (2017), "The rise of crowd logistics: a new way to co-create logistics value", Journal of Business Logistics, Vol. 38, pp. 238-252.

Carbone, V., Rouquet, A. and Roussat, C. (2018), "A typology of logistics at work in collaborative consumption", International Journal of Physical Distribution and Logistics Management, Vol. 48, pp. 570-585.

Chai, Y., Miao, C., Sun, B., Zheng, Y. and Li, Q. (2017), "Crowd science and engineering: concept and research framework", International Journal of Crowd Science, Vol. 1 No. 1, pp. 2-8.

Chen, N., Liu, W., Bai, R. and Chen, A. (2019), "Application of computational intelligence technologies in emergency management: a literature review", Artificial Intelligence Review, Vol. 52, pp. 2131-2168.

Chen, Z., Kolte, P., Kettinger, W.J. and Yoo, S. (2018), “Established companies' strategic responses to sharing economy threats", MIS Quarterly Executive, Vol. 17 No. 1, pp. 23-40. 
Chen, C., Cheng, S., Gunawan, A., Misra, A., Dasgupta, K. and Chander, D. (2014), "TRACCS: a framework for trajectory-aware coordinated urban crowd-sourcing", Second AAAI Conference on Human Computation and Crowdsourcing, Pittsburgh, PA, from November 2-4, pp. 30-40.

David, R.J. and Han, S.-K. (2004), "A systematic assessment of the empirical support for transaction cost economics”, Strategic Management Journal, Vol. 25, pp. 39-58.

Devari, A., Nikolaev, A.G. and He, Q. (2017), "Crowdsourcing the last mile delivery of online orders by exploiting the social networks of retail store customers", Transportation Research Part E: Logistics and Transportation Review, Vol. 105, pp. 105-122.

Ermagun, A. and Stathopoulos, A. (2018), "To bid or not to bid: an empirical study of the supply determinants of crowd-shipping", Transportation Research Part A: Policy and Practice, Vol. 116, pp. 468-483.

Frehe, V., Mehmann, J. and Teuteberg, F. (2017), "Understanding and assessing crowd logistics business models - using everyday people for last mile delivery", Journal of Business and Industrial Marketing, Vol. 32, pp. 75-97.

Gan, M., Yang, S., Li, D., Wang, M., Chen, S., Xie, R. and Liu, J. (2018), "A novel intensive distribution logistics network design and profit allocation problem considering sharing economy", Complexity, Vol. 2018, pp. 1-15, Article ID 4678358. *.

Gansky, L. (2010), The Mesh: Why the Future of Business is Sharing, Portfolio Penguin, Penguin Group, 272 pages.

Gatta, V., Marcucci, E., Nigro, M., Patella, S. and Serafini, S. (2019), "Public transport-based crowdshipping for sustainable city logistics: assessing economic and environmental impacts", Sustainability, Vol. 11, p. 145*.

Gaviria-Marin, M., Merigó, J.M. and Baier-Fuentes, H. (2019), "Knowledge management: a global examination based on bibliometric analysis", Technological Forecasting and Social Change, Vol. 140, pp. 194-220.

Gdowska, K., Viana, A. and Pedroso, J. (2018), "Stochastic last-mile delivery with crowdshipping", Transportation Research Procedia, Vol. 30, pp. 90-100.

Geissinger, A., Laurell, C., Öberg, C. and Sandström, C. (2019), "How sustainable is the sharing economy? On the sustainability connotations of sharing economy platforms", Journal of Cleaner Production, Vol. 206, pp. 419-429.

Gkatzelis, V., Kollias, K. and Roughgarden, T. (2016), "Optimal cost-sharing in general resource selection games”, Operations Research, Vol. 64 No. 6, pp. 1230-1238.

Guiliang, Z., Zhiqiang, L., Wanneng, S., Tianwen, B., Lina, M., Dingxin, W. and Feng, Q. (2017), "Smart savings on private carpooling based on internet of vehicles", Journal of Intelligent and Fuzzy Systems, Vol. 32, pp. 3785-3796.

Hadzikadic, M. and Sun, M. (2010), "Wisdom of crowds in the prisoner's Dilemma context", Advances in Machine Learning II, Springer, Berlin, Heidelberg, pp. 101-118.

Han, Z., Sun, H., Fan, B. and Zhao, Y. (2019), "The general model of atom-type simulation members in crowd network", Proceedings of the 4th International Conference on Crowd Science and Engineering, pp. 161-167.

$\mathrm{He}$ J. and Gu, X. (2018), "Value analysis of shared warehousing system based on web", Computer Integrated Manufacturing Systems, Vol. 24, pp. 2322-2328.

Hensher, D. (2018), "Tackling road congestion - what might it look like in the future under a collaborative and connected mobility model?", Transport Policy, Vol. 66, pp. A1-A8.

Janjevic, M. and Ndiaye, A. (2017), "Investigating the theoretical cost-relationships of urban consolidation centres for their users", Transportation Research Part A: Policy and Practice, Vol. 102, pp. 98-118.

Jaržemskis, A. (2007), "Research on public logistics centre as tool for cooperation", Transport, Vol. 22, pp. 50-54. 


\section{IJCS 5,1}

Karabati, S. and Saym, S. (2008), "Single-supplier/multiple-buyer supply chain coordination: Incorporating buyers' expectations under vertical information sharing: economics of operations and information management", European Journal of Operational Research, Vol. 187, pp. 746-764.

Kong, X., Xu, S.X., Cheng, M. and Huang, G.Q. (2018), "IoT-enabled parking space sharing and allocation mechanisms", IEEE Transactions on Automation Science and Engineering, Vol. 15, pp. 1654-1664.

Kunze, O. (2016), "Replicators, ground drones and crowd logistics a vision of urban logistics in the year 2030", Transportation Research Procedia, Vol. 19, pp. 286-299.

Kunze, O., Wulfhorst, G. and Minner, S. (2016), "Applying systems thinking to city logistics: a qualitative (and quantitative) approach to model interdependencies of decisions by various stakeholders and their impact on city logistics", Transportation Research Procedia, Vol. 12, pp. 692-706.

Li, Y., Zhao, H.V. and Chen, Y. (2019b), "An epidemic model for correlated information diffusion in crowd intelligence networks", International Journal of Crowd Science, Vol. 3 No. 2, pp. 168-183.

Li, M., Lin, P., Xu, G. and Huang, G. (2018), "Cloud-based ubiquitous object sharing platform for heterogeneous logistics system integration”, Advanced Engineering Informatics, Vol. 38, pp. 343-356.

Li, S., Wu, W., Xia, Y., Zhang, M., Wang, S. and Douglas, M. (2019a), "How do crowd logistics platforms create value. An exploratory case study from China", International Journal of Logistics: Research and Applications, Vol. 22 No. 5, pp. 501-518.

Li, W., Wu, W.J., Wang, H.M., Cheng, X.Q., Chen, H.J., Zhou, Z.H. and Ding, R. (2017), “Crowd intelligence in AI 2.0 era", Frontiers of Information Technology and Electronic Engineering, Vol. 18, pp. 15-43.

Liu, H., Wang, Y. and Feng, S. (2018), "Crowd science in the perspective of economics", Proceedings of the 3rd International Conference on Crowd Science and Engineering, pp. 1-4.

Macpherson, A. and Holt, R. (2007), "Knowledge, learning and small firm growth: a systematic review of the evidence", Research Policy, Vol. 36, pp. 172-192.

Martin, M., Lazarevic, D. and Gullström, C. (2019), "Assessing the environmental potential of collaborative consumption: peer-to-peer product sharing in Hammar by Sjöstad”, Sweden. Sustainability, Vol. 11, pp. 1-19.

Mehmann, J., Frehe, V. and Teuteberg, F. (2015), "Crowd logistics - a literature review and maturity model", Innovations and Strategies for Logistics and Supply Chains: Technologies, Business Models and Risk Management. Proceedings of the Hamburg International Conference of Logistics (HICL), Vol. 20, Epubli GmbH, Berlin, pp. 117-145.

Melo, S., Macedo, J. and Baptista, P. (2019), "Capacity-sharing in logistics solutions: a new pathway towards sustainability”, Transport Policy, Vol. 73, pp. 143-151.

Mishra, V. (2018), "Establishing a nexus between sharing economy and entrepreneurial sustainability: a conceptual perusal", AMC Indian Journal of Entrepreneurship, Vol. 1 No. 1, pp. 44-57.

Mladenow, A., Bauer, C. and Strauss, C. (2016), "Crowd logistics': the contribution of social crowds in logistics activities", International Journal of Web Information Systems, Vol. 12, pp. 379-396.

Moore, J. (1996), The Death of Competition: Leadership and Strategy in the Age of Business Ecosystems, HarperCollins Publishers.

Moore, J. (2003), Digital Business Ecosystems in Developing Countries: An Introduction, Berkman Center for Internet and Society, Harvard Law School, available at: http://cyber.law.harvard.edu/bold/ devel03/modules/episodeII.html

Newbert, S.L. (2007), "Empirical research on the resource-based view of the firm: an assessment and suggestions for future research", Strategic Management Journal, Vol. 28, pp. 121-146.

Ocicka, B. and Wieteska, G. (2017), "Sharing economy in logistics and supply chain management", LogForum, Vol. 13 No. 2, pp. 183-193.

Okubo, Y. (1997), "Bibliometric indicators and analysis of research systems: methods and examples", OECD Science, Technology and Industry Working Papers, 1997/01, OECD Publishing, Paris. 
Perrier, L., Lightfoot, D., Kealey, M.R., Straus, S.E. and Tricco, A.C. (2016), "Knowledge synthesis research: a bibliometric analysis", Journal of Clinical Epidemiology, Vol. 73, pp. 50-57.

Pottinger, L. (2018), "Growing, guarding and generous exchange in an analogue sharing economy", Geoforum, Vol. 96, pp. 108-118.

Punel, A. and Stathopoulos, A. (2017), "Modeling the acceptability of crowdsourced goods deliveries: role of context and experience effects", Transportation Research Part E: Logistics and Transportation Review, Vol. 105, pp. 18-38.

Punel, A., Ermagun, A. and Stathopoulos, A. (2018), "Studying determinants of crowd-shipping use", Travel Behaviour and Society, Vol. 12, pp. 30-40.

Qi, W., Li, L., Liu, S. and Shen, Z.J.M. (2018), "Shared mobility for last-mile delivery: design, operational prescriptions, and environmental impact", Manufacturing and Service Operations Management, Vol. 20, pp. 737-751.

Quoniam, L., Hassanaly, P., Baldit, P., Rostaing, H. and Dou, H. (1993), "Bibliometric analysis of patent documents for R\&D management", Research Evaluation, Vol. 3 No. 1, pp. 13-18.

Rudmin, F. (2016), "The consumer science of sharing: a discussant's observations", Journal of the Association for Consumer Research, Vol. 1 No. 2, pp. 198-209.

Sampaio, A., Savelsbergh, M., Veelenturf, L. and VAN Woensel, T. (2017), "Crowd-based City Logistics", SCL Report Series*.

Serafini, S., Nigro, M., Gatta, V. and Marcucci, E. (2018), "Sustainable crowdshipping using public transport: a case study evaluation in Rome", Transportation Research Procedia, Vol. 30, pp. 101-110.

Surowiecki, J. (2004), The Wisdom of Crowds, 2004, Anchor, New York, NY.

Taeihagh, A. (2017), "Crowdsourcing, sharing economies and development", Journal of Developing Societies, Vol. 33, pp. 191-222.

Tong, Y., Yuan, Y., Cheng, Y., Chen, L. and Wang, G. (2017), "Survey on spatiotemporal crowdsourced data management techniques", Journal of Software, Vol. 28, pp. 35-58.

Ukolov, V., Solomatin, A., Solomatin, Y., Chernikov, S. and Ukolov, A. (2016), "Food-sharing economy pattern comparison in UK and Russian markets", International Business Management, Vol. 10, pp. 4268-4282.

Volgger, M., Pforr, C., Stawinoga, A.E., Taplin, R. and Matthews, S. (2018), "Who adopts the Airbnb innovation? An analysis of international visitors to Western Australia", Tourism Recreation Research, Vol. 43, pp. 305-320.

Wallenburg, C. (2009), "Innovation in logistics outsourcing relationships: proactive improvement by logistics service providers as a driver of customer loyalty", Journal of Supply Chain Management, Vol. 45, pp. 75-93.

Wang, F., Ma, X. and Liu, J. (2019), "Demystifying the crowd intelligence in last mile parcel delivery for smart cities”, IEEE Network, Vol. 33 No. 2, pp. 23-29.

Wang, X., Liu, X. and Li, Z. (2018), "A social collaborative urban distribution integration platform", Journal of Interdisciplinary Mathematics, Vol. 21, pp. 1109-1113.

Wang, L., Gauthier, V., Chen, G. and Moreira-Matias, L. (2018), "Special issue on extracting crowd intelligence from pervasive and social big data", Journal of Ambient Intelligence and Humanized Computing, Vol. 9, pp. 2009-2010.

Wang, X.X., Yuen, K., Wong, Y. and Teo, C.-C. (2018), "Consumer participation in last-mile logistics service: an investigation on cognitions and affects", International Journal of Physical Distribution and Logistics Management.*.

Wang, Y., Zhang, D., Liu, Q., Shen, F. and Lee, L.-H. (2016), "Towards enhancing the last-mile delivery: an effective crowd-tasking model with scalable solutions", Transportation Research Part E: Logistics and Transportation Review, Vol. 93, pp. 279-293. 
IJCS
5,1

Williams, C. and Horodnic, I. (2017), "Regulating the sharing economy to prevent the growth of the informal sector in the hospitality industry", International Journal of Contemporary Hospitality Management, Vol. 29, pp. 2261-2278.

Yildiz, B. and Savelsbergh, M. (2019), "Service and capacity planning in crowd-sourced delivery", Transportation Research Part C: Emerging Technologies, Vol. 100, pp. 177-199.

Zhai, J. and Du, Q. (2017), "Economic analysis of logistics information sharing based on network", Review of University of Engenery, Vol. 32, pp. 192-199.

Zhang, C., Kolte, P., Kettinger, W. and Yoo, S. (2018), "Established companies' strategic responses to sharing economy threats", MIS Quarterly Executive, Vol. 17*.

Zinn, W. and Goldsby, T.J. (2017), "The role of academic research in supply chain practice: how much are we contributing?", Journal of Business Logistics, Vol. 38, pp. 236-237.

Zupic, I. and Čater, T. (2015), "Bibliometric methods in management and organization”, Organizational Research Methods, Vol. 18 No. 3, pp. 429-472.

\section{Further reading}

Castillo, V., Bell, J., Rose, W. and Rodrigues, A. (2018), "Crowdsourcing last mile delivery: strategic implications and future research directions", Journal of Business Logistics, Vol. 39, pp. 7-25.

Ernst, C., Mladenow, A. and Strauss, C. (2017), "Collaboration and crowdsourcing in emergency management", International Journal of Pervasive Computing and Communications, Vol. 13, pp. 176-193.

Frenken, K. (2017), "Sustainability perspectives on the sharing economy", Environmental Innovation and Societal Transitions, Vol. 23, pp. 1-2.

Frenken, K. and Schor, J. (2017), "Putting the sharing economy into perspective", Environmental Innovation and Societal Transitions, Vol. 23, pp. 3-10.

Gruchmann, T., Melkonyan, A. and Krumme, K. (2018), "Logistics business transformation for sustainability: assessing the role of the lead sustainability service provider (6PL)", Logistics, Vol. 2 No. 4, p. 25.

Huarng, K.H. (2018), "Entrepreneurship for long-term care in sharing economy", International Entrepreneurship and Management Journal, Vol. 14, pp. 97-104.

Key, T. (2017), "Domains of digital marketing channels in the sharing economy", Journal of Marketing Channels, Vol. 24, pp. 27-38.

Kung, L.C. and Zhong, G.Y. (2016), "Platform delivery: a game-theoretic analysis of a new delivery model in the sharing economy", Pacific Asia Conference on Information Systems, PACIS 2016 Proceedings, p. 104.

Kung, L.-C. and Zhong, G. (2017), "The optimal pricing strategy for two-sided platform delivery in the sharing economy", Transportation Research Part E: Logistics and Transportation Review, Vol. 101, pp. 1-1-12.

Kupriyanovsky, V., Sokolov, I., Talashkin, G., Dunaev, O., Zazhigalkin, A., Raspopov, V., Namiot, D. and Pokusaev, O. (2017), "Digital sharing economy: technologies, platforms and libraries in industry, construction, transport, and logistics", International Journal of Open Information Technologies, Vol. 5, pp. 56-75.

Le, T.V., Stathopoulos, A., VAN Woensel, T. and Ukkusuri, S.V. (2019), "Supply, demand, operations, and management of crowd-shipping services: a review and empirical evidence", Transportation Research Part C: Emerging Technologies, Vol. 103, pp. 83-103.

Lirn, T., Yeo, G. and Han, J. (2017), "Sharing economics and the innovation of Asian shipping and logistics industry", Asian Journal of Shipping and Logistics, Vol. 33, pp. 51-52.

Mesarč, P., Knapcikova, L., Konings, R., Sánchez-Sierra, S., Caballero-Morales, S., Sánchez-Partida, D. and Malkus, T. (2018), "Increase of efficiency of logistics flows in sharing economy conditions of a specific company", Acta Logistica - International Scientific Journal about Logistics, Vol. 5 No. 3 , pp. 65-69. 
Miglietta, A. and Parisi, E. (2017), Civic CrowdFunding: Sharing Economy Financial Opportunity to Smart Cities. Smart Cities Atlas.159-172. Tracts in Civil Engineering, Springer, Cham.

Niu, Y., Yang, Z., Chen, P. and Xiao, J. (2018), “Optimizing the green open vehicle routing problem with time windows by minimizing comprehensive routing cost", Journal of Cleaner Production, Vol. 171, pp. 962-971.

Ranard, B., Ha, Y., Meisel, Z., Asch, D., Hill, S., Becker, L., Seymour, A. and Merchant, R. (2014), "Crowdsourcing - harnessing the masses to advance health and medicine, a systematic review", Journal of General Internal Medicine, Vol. 29, pp. 187-203.

Rodríguez-Antón, J., Alonso-Almeida, M., Rubio-Andrada, L. and Pedroche, M. (2016), “Collaborative economy. An approach to sharing tourism in Spain. CIRIEC-Espana revista de economia publica”, Socialy Cooperativa, Vol. 88, pp. 259-283.

Scavarda, M., Seok, H., Puranik, A. and Nof, S. (2015), "Adaptive direct/indirect delivery decision protocol by collaborative negotiation among manufacturers, distributors, and retailers", International Journal of Production Economics, Vol. 167, pp. 232-245.

Schor, J. (2017), "Does the sharing economy increase inequality within the eighty percent? Findings from a qualitative study of platform providers", Cambridge Journal of Regions, Economy and Society, Vol. 10, pp. 263-279.

Szmelter, A. (2018), "Mobility-as-a-service - a challenge for it in the age of sharing economy", Information System in Management, Vol. 7 No. 1, pp. 59-71.

Szoltysek, J. (2016), "Sharing economy and urban logistics - on connections".

Transfield, D., Denyer, D. and Smart, P. (2003), "Towards a methodology for developing evidenceinformed management knowledge by means of systematic review", British Journal of Management, Vol. 14 No. 3, pp. 207-222.

Vecchio, G. and Tricarico, L. (2019), "'May the force move you': roles and actors of information sharing devices in urban mobility", Cities, Vol. 88, pp. 261-268.

Verhoeven, P., Sinn, F. and Herden, T. (2018), "Examples from blockchain implementations in logistics and supply chain management: exploring the mindful use of a new technology", Logistics, Vol. 2 No. 3, p. 20.

Watanabe, C., Naveed, K., Neittaanmäki, P. and Fox, B. (2017), "Consolidated challenge to social demand for resilient platforms - lessons from Uber's global expansion”, Technology in Society, Vol. 48, pp. 33-53.

Wiles, A. and Crawford, A. (2017), "Network hospitality in the share economy: understanding guest experiences and the impact of sharing on lodging", International Journal of Contemporary Hospitality Management, Vol. 29, pp. 2444-2463.

Yao, B., Qui, R., Fan, D., Liu, A. and Buhalis, D. (2019), "Standing out from the crowd - an exploration of signal attributes of Airbnb listings", International Journal of Contemporary Hospitality Management, Vol. 31 No. 12, pp. 4520-4542.

\section{Corresponding author}

Laurence Saglietto can be contacted at: laurence.saglietto@gredeg.cnrs.fr 


$\begin{array}{ll}\text { IJCS } & \text { Appendix } \\ 5,1 & \end{array}$

54

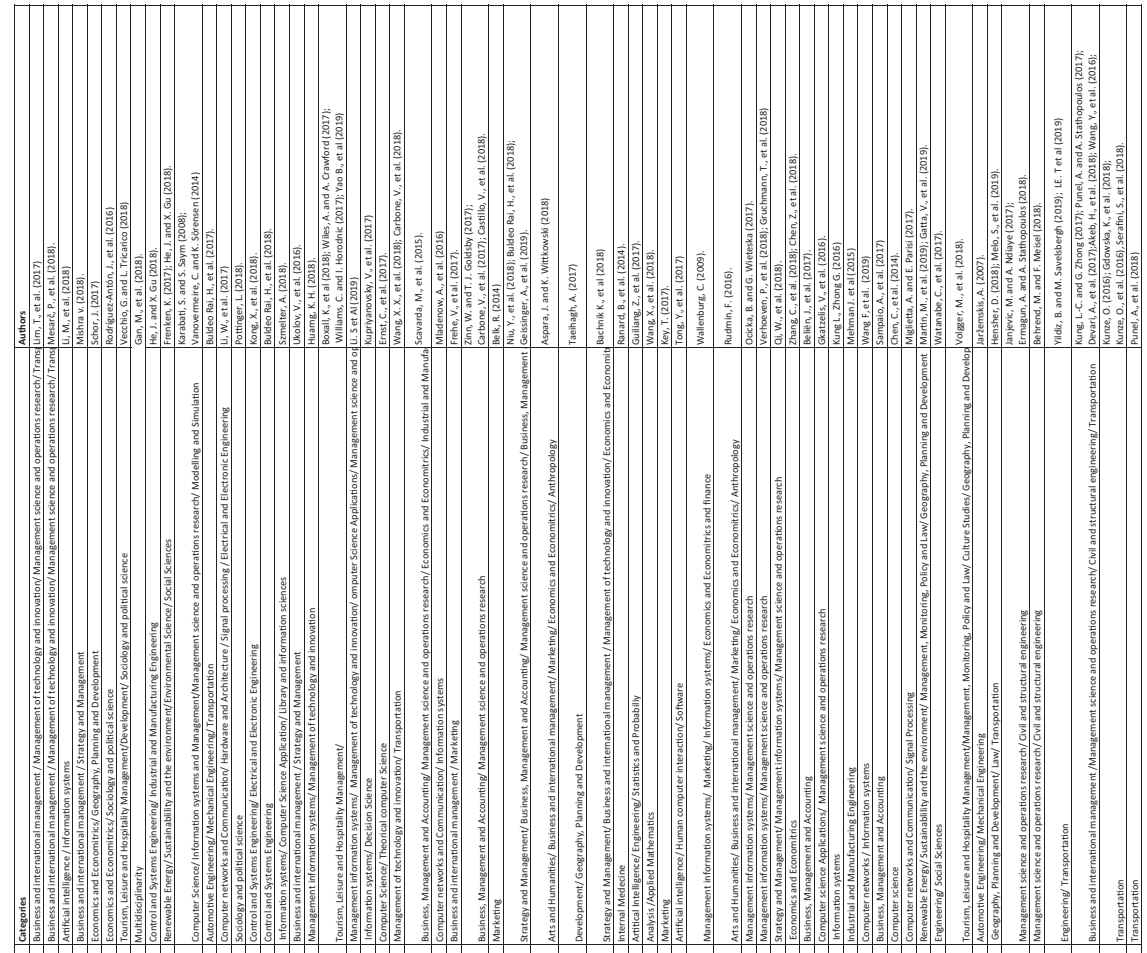

Figure A1.

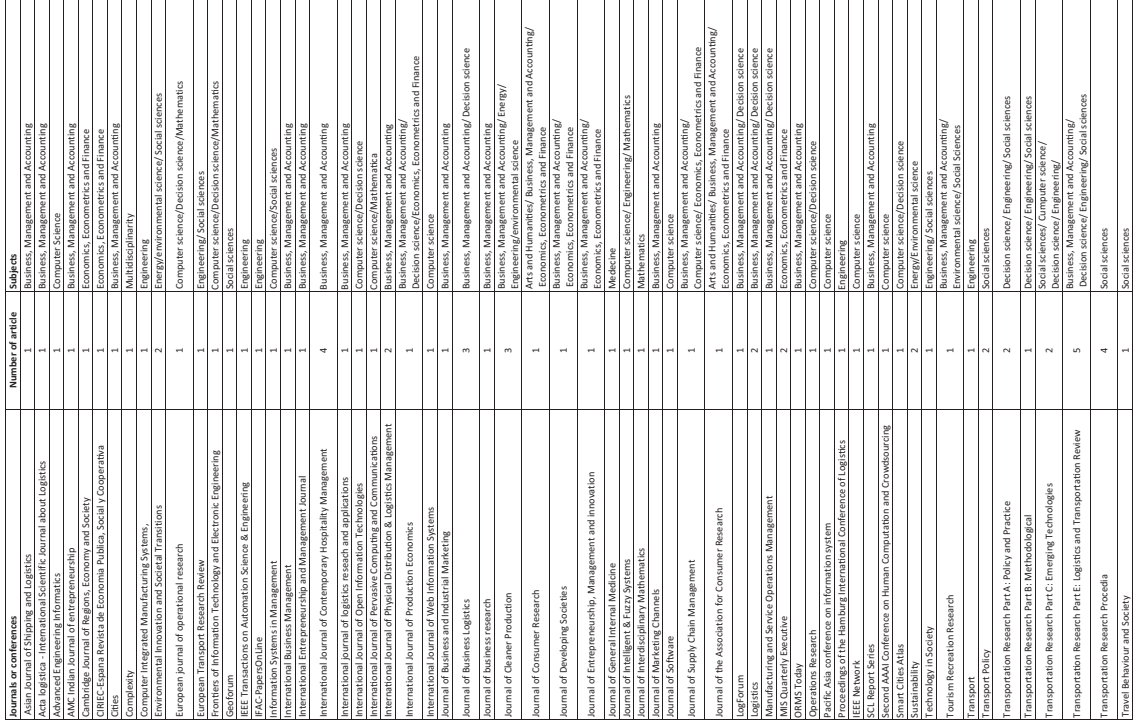

